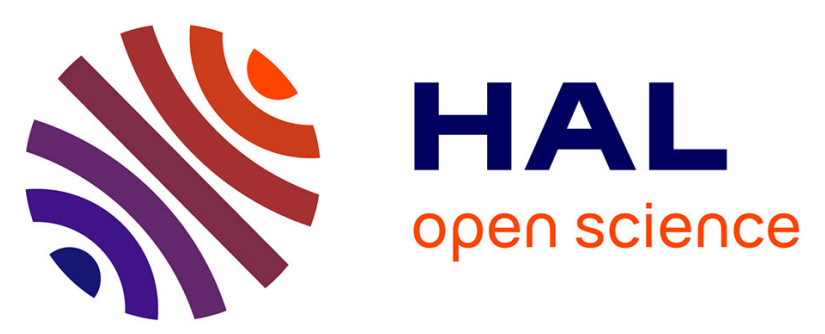

\title{
A phase-II study of combination of pegylated interferon alfa-2a and capecitabine in locally advanced or metastatic renal cell cancer
}

\author{
Kaisa Leea Sunela, Sanna Koskinen, Pirkko-Liisa Kellokumpu-Lehtinen
}

\section{- To cite this version:}

Kaisa Leea Sunela, Sanna Koskinen, Pirkko-Liisa Kellokumpu-Lehtinen. A phase-II study of combination of pegylated interferon alfa-2a and capecitabine in locally advanced or metastatic renal cell cancer. Cancer Chemotherapy and Pharmacology, 2009, 66 (1), pp.59-67. 10.1007/s00280-009-11342 . hal-00568270

\author{
HAL Id: hal-00568270 \\ https://hal.science/hal-00568270
}

Submitted on 23 Feb 2011

HAL is a multi-disciplinary open access archive for the deposit and dissemination of scientific research documents, whether they are published or not. The documents may come from teaching and research institutions in France or abroad, or from public or private research centers.
L'archive ouverte pluridisciplinaire $\mathbf{H A L}$, est destinée au dépôt et à la diffusion de documents scientifiques de niveau recherche, publiés ou non, émanant des établissements d'enseignement et de recherche français ou étrangers, des laboratoires publics ou privés. 
Kaisa Sunela ${ }^{1}$, Sanna Koskinen ${ }^{2}$, Pirkko-Liisa Kellokumpu-Lehtinen ${ }^{1,2}$

A phase-II study of combination of pegylated interferon alfa-2a and capecitabine in locally advanced or metastatic renal cell cancer

Informative title: pegylated interferon alfa-2a and capecitabine for RCC patients

${ }^{1}$ Tampere University Hospital/ Oncology

P.O. BOX 2000

33521 Tampere

Finland

${ }^{2}$ University of Tampere/ Medical School/ Oncology

33014 University of Tampere

Corresponding author: Kaisa Sunela

kaisa.sunela@pshp.fi

tel. +358331163082

fax. +358331163003 


\begin{abstract}
Purpose Combination of capecitabine and interferon has shown activity in metastatic renal cell carcinoma. Pegylated interferons might have more clinical activity and fewer side effects. This study evaluated the efficacy, tolerability and safety of the combination of capecitabine and pegylated interferon alfa-2a.

Methods In this open-label, single institution, non-randomized phase II first-line study 26 patients were included. Capecitabine was administered $2000 \mathbf{~ m g} / \mathbf{m}^{2}$ daily for 14 days followed by one week rest. Pegylated interferon alfa-2a was given as once weekly injections with a fixed dose of $180 \mu \mathrm{g}$. Overall survival, progression-free survival and response rates were evaluated; safety and tolerability were monitored.

Results Response rate was $27 \%$, with $4 \%$ complete responses. Stable disease was achieved in 42 $\%$. The treatment discontinued in $4(15 \%)$ patients before first response evaluation because of toxicity. The median progression-free survival was 7.5 months; the median overall survival was 17 months. Grade 3-4 toxicity was seen in $46 \%$ of patients, but in $93 \%$ of cycles no serious toxicity was experienced. Dose reductions had to be done, but in $81 \%$ of cycles intensity of $70 \%$ or more was possible. Quality of life was better in cycle five than in the base line.

Conclusions The combination had moderate, but manageable toxicity. In the future studies, lower dose for capecitabine is recommended. The combination was active and the response rates seen here were in line with phase II studies on former combinations of non-pegylated interferons. One complete remission was achieved.
\end{abstract}

Keywords renal cell carcinoma, immunotherapy, interferon, pegylated, chemotherapy, capecitabine 


\section{Background}

Until very recently, renal cell cancer (RCC) has had very few available oncological treatments with at least moderate efficacy. Interferon (IFN) has been reported to have antitumor activity against RCC already in 1983 producing partial responses (PR) to $26 \%$ of patients in the early studies [1]. The mechanisms of action of IFN are various and still partly unclear. IFN modulates cancer cell growth and differentiation by regulation of cell cycle, affects cellular communication and intracellular signaling making cells to undergo apoptosis, but also induces nonapoptotic cell death. The effects of IFN are translated in the direct tumour cell growth inhibition or death and in the stimulation of an antitumor immune response. It also upregulates expression of MCH class I antigens which favours tumor cell recognition by specific cytolytic $\mathrm{T}$ cells as well as the activation of natural killer cells. IFN has postgenomic effects based on the regulation of protein synthesis and on the selective translation of proteins participating in growth arrest and apoptosis. IFN also produces a link between innate and adaptive immune responses and interferes with tumourmediated angiogenesis. [2] However, IFN has moderate toxicity and the dosing is three to five times a week given as subcutaneous injections. Therefore new formulations have been developed and two pegylated interferons are now commercially available. These are chemically modified by covalent linkage of polyethylene glycol (PEG) polymer to enhance pharmacokinetic characteristics and reduce immunogenicity. [3, 4]

Pegylated interferon-alfa-2a (Pegasys $\left.{ }^{\circledR}\right)$ belongs to the second generation of pegylated interferons, with a $40 \mathrm{kd}$ PEG-moiety. After injection serum concentrations are measurable in six hours and stay close to peak from day three to eight allowing once-weekly dosing which might improve efficacy compared with non-pegylated interferons. Steady-state is seen from week five of therapy, but serum concentrations increase with chronic dosing to 2.5 -fold. Side-effects are most commonly fatigue, fever, headache, myalgia, nausea and decreased appetite and elevated liver values, anemia, thrombocytopenia and leuko-/neutropenia. In phase I studies PRs were seen in $19 \%$, stable disease (SD) in $48 \% ; 450 \mu \mathrm{g} /$ week was recommend for further studies as a single-agent therapy. [3] In phase II studies responses were seen in $13 \%$ of patients, complete response (CR) in $2.5 \%$. The toxicity was mostly mild to moderate; grade 3-4 toxicity was seen as neutropenia, fatigue, nausea/ vomiting and elevated hepatic transaminase values. [5]

An alternative to pegylated interferon-alfa-2a is pegylated interferon-alfa-2b (PEG-Intron®), which has a single PEG-moiety and a molecular weight of $12 \mathrm{kd}$. As a single agent therapy it is well tolerated up to $6.0 \mu \mathrm{g} / \mathrm{kg} / \mathrm{week}$, which achieves an exposure comparable to $180 \mathrm{MIU}$ non-pegylated interferon per week. $[4,6]$ In a phase II study with single agent therapy with escalating dose 3.0 to $6.0 \mu \mathrm{g} / \mathrm{kg} / \mathrm{week}$, the overall response rate was $13.6 \%$, with $4.5 \%$ CRs (one patient). Median overall survival (OS) was 13 months; in $9 \%$ of patients the response remained over six months. In this study fatigue was the major dose-limiting factor; in $22.7 \%$ of patients grade 3-4 fatigue was reported. No grade 3-4 hematologic toxicity or liver enzyme elevations were seen, but $55 \%$ of patients required dose reductions. [7]

Chemotherapy is considered mostly ineffective in RCC [8], but 5-fluorouracil as a continuous infusion has shown some (less than $10 \%$ ) PRs [9]. Capecitabine is an oral fluoropyrimidine, a prodrug which is converted to 5-fluorouracil via enzyme pathway. Kidney cancer cells contain a considerable amount of thymidine phosphorylase (TP), a key enzyme converting capecitabine to active 5-FU. [10] As a single-agent capecitabine gives minor responses even in third line therapy, but in most patients no response or only SD is observed [11, 12]. 
The rationale for combination of capecitabine and interferon, is that cytokines, including interferon increase intratumoral levels of TP especially given prior to fluoropyrimides. This increases the efficacy of capecitabine. [13,14] The continuous infusion of 5 -fluorouracil, similar to the effect of capecitabine, is reported to potentiate the action of interferon-alfa-2b producing a $43 \%$ response rate with $19 \% \mathrm{CRs}$, with mild toxicity. These responses were durable as the mean duration of response was almost two years. [15] However, the response rates in multicenter randomized trials are similar to those for cytokines alone [16].

Combinations of capecitabine and non-pegylated interferon- $\alpha$ has been tested in phase I and II studies, which have shown that this combination is most commonly well tolerated and it has some clinical activity and manageable toxicity [17-19]. PRs and SD even as a second- or third-line treatment are seen with capecitabine as a single-agent therapy or in combination with interferon-alfa [20, 21]. In triplet combinations immunomodulatory drug thalidomide is added to combination [22]. Also combination of capecitabine, interferon-alfa-2a, IL-2 and oral 13-cis retinoic acid has been reported [23]. Only reported study on the combination of capecitabine $\left(1000 \mathrm{mg} / \mathrm{m}^{2}\right.$ twice daily days $1-14$, cycle 28 days) and pegylated interferon-alfa (50 $\mu \mathrm{g}$ weekly s.c.) is done with PEGIntron ${ }^{\circledR}$. In this phase II study also subcutaneous low dose interleukin-2 (IL-2) and oral 13-cisretinoid acid were in the treatment schedule. This treatment was well tolerated; responses were seen in $53.6 \%$ of patients. [24] The combination of capecitabine and pegylated interferon-alfa-2a is not reported in the literature before this study.

\section{Patients and methods}

This was an opel-label, single institution, nonrandomized phase II study. Primary objective was to characterize efficacy, safety and tolerability of PEG-IFN-alfa-2a given once weekly s.c. and capecitabine given per orally. For efficacy progression-free survival (PFS), overall survival (OS) and response rate were assessed; for tolerability premature withdrawals and dose reductions because of laboratory abnormalities or adverse events and for safety adverse events, laboratory test results and vital signs were recorded. The study protocol was approved by the Pirkanmaa Hospital District ethical committee.

Eligibility criteria included: age 18 to 80 years, informed consent, histologically or cytologically verified locally advanced or metastatic RCC with or without prior nephrectomy, evaluable or measurable disease (RECIST), performance status of Zubrod 0-2 and adequate renal (serum creatinine less than $180 \mathrm{mmol} / \mathrm{l}$ ) and hepatic function (bilirubin, aspartate aminotransferase (ASAT) and glutamyl transferase (GT) less than 1.5 times the upper limit of normal values).

Exclusion criteria included pregnant or lactating women, other malignancies than RCC excluding basal or squamous cell carcinomas of the skin and carcinoma in situ of the uterine cervix, metastases in central nervous system (brain computed tomography was not required for asymptomatic patients), chronic heart failure (New York Heart Association status III-IV), instable angina pectoris, acute myocardium infarction within the past 12 months before study entry, history of difficult renal, hepatic, neurological or psychiatric disease, untreated depression, serious infection or wide-field radiotherapy within the previous four weeks. Prior treatment with interferon was not allowed.

Pretreatment evaluation included a medical history (including primary TNM classification and grade, sites of metastases, type of surgery, given radiotherapy), clinical examination, electrocardiography, complete blood count, assessment of plasma creatinine, calcium and protein levels and liver function tests: alkaline phosphatase (AFOS), alanine aminotransferase (ALAT), 
ASAT, GT, bilirubin. Radiographic studies (bone scan, thorax x-ray and abdominal ultrasound or whole body computed tomography) were assessed within 14 days prior to the initiation of therapy. In six first patients laboratory studies were performed on a weekly basis during the first three cycles, and at the end of each cycle thereafter. Radiographic studies, as required for assessment of measurable disease, were performed after two cycles, then every three cycles thereafter. Response was assessed according to RECIST criteria [25]. No external verification of response was employed. Toxicity was assessed according to NCI-CTCAE criteria [26] and quality of life according to EORTC QLQ-3 criteria [27], both in base line and after every cycle. Treatment was continued until 52 weeks or clinically significant progression, patient's withdrawal, unacceptable toxicity or 12 weeks after confirmation of CR.

Between 2003 and 2008, 26 patients with advanced RCC entered trial (demographics in Table 1). The median age of patients was 63.5 years (range 46-81). One patient was older than the inclusion criteria required. However, this patient tolerated the treatment well and achieved complete response. Two patients were not operated before this trial.

PEG-IFN-alfa-2a was administered by subcutaneous injection at a fixed dose of $180 \mu \mathrm{g}$ once weekly. As the study combination is not reported in the literature, PEG-IFN dosing was chosen to be the smallest with clinical efficacy [3]. No dose modifications were done, but the injection was withheld for grade 3-4 toxicity and for grade 2 toxicity if it was related to interferon. Capecitabine was administered twice daily at a dose of $2000 \mathrm{mg} / \mathrm{m}^{2}$ per day on days 1-14 of a 21-day cycle. Treatment was withheld in the event of any toxicity with severity exceeding grade two. With grade one toxicity, no delays or dose modifications were done. With grade two toxicity, treatment was withheld until toxicity improved to grade one or better, if the event was not treatable with symptomatic medication. If the same event reappeared, treatment was again withheld until toxicity improved to grade one or better, then restarted with $25 \%$ lower dose of capecitabine. Grade three toxicity lead to withhold of therapy until it resolved to grade one or better, then restarted with $25 \%$ lower dose of capecitabine. The reductions were made with $500 \mathrm{mg}$ steps (the tablet size). As a dose reduction was recorded the lower dose of given therapy or shorter administration of capecitabine or omitted injection. Grade four toxicity lead to discontinuation of the therapy.

The follow-up was every two months until six months after the end of the study treatment and then every three to six months up to two years. The progression date and the cause and date of death were recorded.

The investigators designed and initiated the study, collected, analyzed and maintained the data. PEF-IFN (Pegasys ${ }^{\circledR}$ ) and capecitabine (Xeloda ${ }^{\circledR}$ ) were received from Roche Finland and grants from the Competitive Research Funding of Tampere University Hospital, Pirkanmaa Hospital District.

\section{Results}

The median of given cycles was 5.5 (range 1-18). In $30 \%$ of patients the treatment discontinued before the third cycle because of toxicity or progressive disease. The median follow-up was 10.5 months (range 0-50 months).

The overall response rate was $27 \%$ : PR was achieved in $23 \%$ and CR in one patient (4\%). SD was seen in $42 \%$ of patients and progressive disease in $15 \%$. No response evaluations were done in 4 (15\%) patients because of toxicity related early discontinuation of the study treatment. In the end of study treatment, PR remained in $15 \%$ and SD in $27 \%$, others progressed. CR remained throughout 
the follow-up period. The median PFS was 7.5 months (range 1-51+ months). Four patients have not progressed in the follow-up. The median OS was 17 months (range 2-55+ months). The oneyear survival was $77 \%$; the two-year survival rate was $38 \%$. Kaplan-Meier estimates of overall and progression-free survival are shown in Fig. 1. Second-line treatment was given to $72 \%$ of patients.

In seven responders $(C R+P R)$ the median age was 66 (range 49-81). Previous nefrectomy was performed to $86 \%$ of these patients. Single site of metastases was seen in $86 \%$ and only pulmonary metastases in $43 \%$. Primarily metastatic disease was noticed in $43 \%$ of responders. One patient with CR had T2N0M0 grade IV disease operated six months before relapse (abdominal lymph nodes) was noticed.

The clinical toxicity of the study combination is shown in Table 2, percentages are shown per patient $(n=26)$ and per given cycle $(n=183)$ : grade 1-2 and grade 3-4 toxicities are combined. Fatigue and nausea were the most common toxicities. Only $12 \%$ of patients did not experience nausea at all and $4 \%$ did not experience fatigue. When counted per cycle, in $66 \%$ of given cycles patients experienced fatigue of any grade, nausea of any grade was seen in $33 \%$ of the treatment cycles. Hand-foot syndrome was seen in $39 \%$ of cycles, but $83 \%$ of the patients did not experience this toxicity. The grade $3-4$ toxicity (\% of patients) was recorded on fatigue (23\%), nausea (12\%), constipation (4\%), diarrhea (15\%), stomatitis $(4 \%)$ and hand-foot syndrome (4\%). Also one treatment-related pulmonary embolus and one hematoma of the gall bladder were recorded (grade 4), one patient experienced grade 3 dyspnea. No treatment related deaths occurred. Other, miscellaneous toxicity of any grade was experienced by $77 \%$ of patients during the study treatment; mostly these were grade 1-2. The following toxicities were listed: thrombophlebitis, decreased appetite, nail problems, dryness of mouth, abdominal pain, conjunctivitis and blurriness of the vision.

The hematological and blood chemistry toxicity is shown in Table 3, percentages are shown again per patient and per given cycle. The most common toxicities were anemia, leucopenia, neutropenia, hypoalbuminemia and the elevation of liver values (ASAT). Leucopenia was seen in $69 \%$ of patients, anemia in $65 \%$ and elevation of liver values were seen in $62 \%$. Anemia was also the most common toxicity when counted per given cycle: in $54 \%$ of cycles. Neutropenia and thrombocytopenia were seen in $46 \%$ and hypoalbuminemia in $45 \%$ of cycles. Grade 3-4 toxicity was seen as neutropenia, leucopenia and elevation of liver values.

Altogether $46 \%$ of patients experienced grade 3-4 toxicity. However, in $93 \%$ of cycles patients experienced only mild or no toxicity. Three patients $(11.3 \%)$ experienced grade 4 toxicity which lead to discontinuation of the study treatment: bloody diarrhea in two patients and synchronous pulmonary embolus and hematoma of the gall bladder in one patient.

In the evaluation of quality of life patients experienced the physical and psychological well being stable (Fig. 2). There was no statistically significant difference in the quality of life when tested in base line and in cycles five and ten $(\mathrm{p}=0.76)$.

The dose reductions are shown in Table 4. The most common indications for dose reductions were elevation of liver values and neutropenia. No dose reductions were needed in $15 \%$ of patients and in $39 \%$ of cycles. In $50 \%$ of patients and in $39 \%$ of given cycles was needed one dose reduction. Altogether $64 \%$ of dose reductions were because of abnormal laboratory values (anemia, leuco- or neutropenia, thrombocytopenia, elevated liver values) which did not cause any clinical problems, but delayed the next cycle. One patient needed dose reduction five times, but 
continued in the study because of clinical benefit. In some cases there were multiple reasons to dose reductions. Dose delays were needed in $46 \%$ of patients and in $14 \%$ of given cycles. These delays were one to two weeks in duration. The dose intensity of capecitabine was $90-100 \%$ in $40 \%$ of cycles, $70-79 \%$ in $36 \%$ of cycles and $50-59 \%$ in $14 \%$ of cycles. Some injections of pegylated interferon were omitted in $35 \%$ of patients and in $87 \%$ of cycles because of grade 2-3 hematological toxicity or elevated liver values.

The reason for discontinuation of the treatment was toxicity in 11 patients (38\%), progressive disease in $10(35 \%)$ and non-treatment-, non-cancer-related death in one $(3 \%)$. In three patients $(11.5 \%)$ treatment was given up to one year and according to protocol discontinued then. One patient discontinued the treatment in complete remission 12 weeks after the confirmation of the response. Also congestive heart failure, infection and second malignancy were reasons for discontinuations, each in one patient. Three patients had two different reasons for discontinuation. Those who discontinued the study because of serious clinical side effects did it during the first cycles, after that there were mostly elevated liver values which prevented the continuation of the study treatment.

\section{Discussion}

The study combination with capecitabine and pegylated interferon-alfa-2a was active: $27 \%$ of patients achieved response including $4 \%$ of CRs. Most patients who responded here had only one site of metastases and half of them had only pulmonary metastases. Other single sites were abdominal and mediastinal lymph nodes. Typical responders to IFN are patients with only pulmonary metastases [1]. The current combination proved efficacy also in other patients. The age range of responders was wide and even the oldest patient (81 years) tolerated the treatment well.

The achieved response rate is in line with phase II studies done with the combination of capecitabine and non-pegylated interferon: 12 to $24 \%$ overall response rates are reported, with 3-4 $\%$ CRs; SD was seen in 36-38 \% of patients $[18,19]$. The triplet combination with thalidomide does not produce better responses: PRs were seen in $20 \%$, SD in $28 \%$ [22]. When IL-2 is added to combination $[23,24]$ more responses and longer PFS and OS are achieved. With the four-drug combination with IL-2 and 13-cis retinoic acid is reported response rate of $34 \%$, with $7 \%$ CRs and $40 \%$ of patients presented with SD [23]. Again, in the phase II study done with capecitabine, pegylated interferon-alfa-2b, IL-2 and 13-cis retinoic acid is reported responses in $53.6 \%$ of patients, with $24 \%$ CRs. SD was achieved in $34 \%$. The median PFS was 14.7 months and the median OS 27.9 months. [24] When capecitabine is combined with another chemotherapy agent gemcitabine responses are seen in $15.8 \%-22 \%$ of patients in phase I-II studies [28, 29], which is quite comparable to responses in different combinations of chemoimmunotherapy with interferon.

Cytokines have been tested in combinations without chemotherapy regimens in hope for achieving more efficacy. When PEG-interferon is combined with IL-2 alone, the response rate is $30.2 \%$ with $3.8 \% \mathrm{CRs}$, which is comparable to the four-drug combinations [23, 24] or high dose IL-2 alone. The median duration of response was 11 months. This schedule consisted of PEG-IFN-2b 2.0 $\mu \mathrm{g} / \mathrm{kg} /$ week and IL-2 $5 \mathrm{MIU} / \mathrm{m}^{2} \mathrm{x} 3$ day 1 , then once daily five days a week, both for four weeks followed by two weeks rest. [30] In other schedule the pegylated interferon-alfa- $2 b$ was given 3.0 $\mu \mathrm{g} / \mathrm{kg} /$ weekly and IL-2 $20 \mathrm{MIU} / \mathrm{m}^{2}$ three times a week at weeks 1 and 4 , and $5.0 \mathrm{MIU} / \mathrm{m}^{2}$ three times a week during weeks 2-3 and 5-6. PRs were seen only in $15 \%$ of patients, SD was achieved in $68 \%$. PFS was 9.0 months and OS 31.9 months. [31] 
Toxicity of the study combination was manageable, but grade $3-4$ side effects were seen in $46 \%$ of patients. Dose reductions were needed in $85 \%$ of patients and in $39 \%$ of cycles. Despite of reductions the response remained in most patients. This need to reductions has been seen already in previous studies done with non-pegylated interferon. In the first phase I trial the combination of capecitabine $\left(825-1000 \mathrm{mg} / \mathrm{m}^{2}\right.$ twice daily for 14 days, followed by one week rest) and non-pegylated interferon-alfa-2b (1.5-3.0 MIU/m ${ }^{2}$ three times a week) had moderate toxicity, mostly mild nausea/ vomiting, diarrhea and hand-foot syndrome. The majority of patients experienced malaise, fever and chills related to interferon. Grade one hepatic toxicity occurred infrequently and hematologic toxicity was generally mild: thrombocytopenia was seen in $33 \%$ of patients and neutropenia in $37 \%$. [17] Since then, in phase II study done with capecitabine (1250 $\mathrm{mg} / \mathrm{m}^{2}$ twice daily for 14 days followed by one week rest) and non-pegylated IFN (6 MIU x 3 /week) grade 3-4 toxicities were seen in $48 \%$ including fatigue, nausea, hand-foot syndrome, anorexia, vomiting, anemia and neutropenia. Toxicity was considered acceptable, but dose reductions had to do in $48 \%$ and dose delays were necessary in $16 \%$ of patients. Capecitabine dose of $1000 \mathrm{mg} / \mathrm{m}^{2}$ twice daily was recommended to further studies. [18] In another phase II study the starting dose with capecitabine was $1000 \mathrm{mg} / \mathrm{m}^{2}$ twice daily on days $1-14$, but because of toxicity requiring dose reductions during the first cycle the dose was reduced to $825 \mathrm{mg} / \mathrm{m}^{2}$ twice daily. Interferon was given $3.0 \mathrm{MIU} / \mathrm{m}^{2}$ thrice a week. Toxicity was considered moderate to severe; dose reductions were required in $88 \%$ of patients and $19 \%$ of patients discontinued therapy secondary to toxicity. Grade 3-4 toxicity was seen in $78 \%$, most commonly gastrointestinal and hand-foot syndrome. [19] In the study of combination of capecitabine and pegylated interferon-alfa-2b grade 3-4 toxicity was seen in $21.9 \%$ including nausea and vomiting, neutropenia, anemia and thrombocytopenia. [24] In the future, in this combination with pegylated interferon-alfa-2a the dose level for capecitabine should be $1600 \mathrm{mg} / \mathrm{m}^{2}$ per day as the dose intensity over $70 \%$ was here tolerable in $81 \%$ of cycles (Table 4).

In the triplet combination (capecitabine $1900 \mathrm{mg} / \mathrm{m}^{2} /$ day days $1-14$; cycle 21 days, IFN- $\alpha 1 \mathrm{MIU}$ daily without interruptions and thalidomide $400 \mathrm{mg}$ daily) the dose reductions of capecitabine were required in $76 \%$ of patients. The most common grade 3-4 toxicity was hand-foot syndrome; anemia occurred in $4 \%$, but no other grade 3-4 hematological toxicity was seen. [22] In the four-drug combination of capecitabine, interferon-alfa-2a, IL-2 and oral 13-cis retinoic acid toxicity was mild. [23] When capecitabine is combined with gemcitabine, the combination is reported to be too toxic in phase I study despite of dose reductions [28], but in phase II study this combination had moderate and manageable toxicity [29], even when gemcitabine was given with bigger dose than in the phase I study.

Toxicity of pegylated interferon-alfa seems to be schedule dependent and sometimes unpredictable. Also, it seems that two available pegylated interferons have different toxicity scale. This is probably in correlation with molecular weight. A 40-kd PEG moiety of interferon-alfa-2a cannot be excreted by the kidneys and is not quickly metabolized; therefore the PEG may accumulate in the liver, which increases the risk for toxicity especially in the long-term administration [6]. The combination of pegylated interferon-alfa-2a and IL-2 produces in some schedules inacceptable toxicity: grade 3 4 cardiac toxicity was seen in $17 \%$ and central nervous system events in $11.3 \%$. The schedule was abandoned because of the toxicity, which remained unexplained as the serum levels of either of the drugs were not increased. Some pharmacodynamic effect was suspected; capillary leak by IL-2 may have increased the end organ concentrations. [30] In other schedule toxicity was moderate; the most common toxicities were nausea and vomiting, diarrhea, fatigue, fever, transient elevation in liver transaminases, leucopenia, thrombocytopenia and anemia. Most of these side effects were mild. [31] 
Current treatment guide lines are recommending tyrosine kinase inhibitors (TKI), combination of bevacizumab and non-pegylated interferon or temsirolimus as primary choices to the first line treatment of metastatic RCC. The choice should be done according to tolerability of the treatment and prognostic factors. [32] With the combination of VEGF inhibitor bevacizumab and non-pegylated IFN, PFS was 10.2 months, OS 19.9 months and response rate $31 \%$. This combination is usually well tolerated, but grade 3-4 fatigue, diarrhea, anemia, neutropenia and thrombocytopenia are seen. Proteinuria, thromboembolic events and gastrointestinal perforation are additional side effects concerning treatment with bevacizumab. [33] TKI sunitinib has proved efficacy in the first line treatment with response rate of $47 \%$, PFS of 11 months and OS of 26.4 months. As the current combination, sunitinib causes grade 3-4 diarrhea, fatigue, nausea and vomiting and hand-foot -syndrome, but additionally also hypertension. Grade 3 leuco- and neutropenia, thrombocytopenia and elevated liver values are also seen. $[34,35]$ Temsirolimus is indicated to RCC patients with poor prognosis: median OS of 10.9 months and PFS of 5.5 months are reached. It also causes grade 3-4 hematological side effects and asthenia. Particular side effects concerning this treatment are hyperlipidemia, hyperglycemia and pneumonitis. [36] The current study combination did not show any new side effects which were not known from the single agent studies. We did not select patients according to risk factors, but the achieved response rate, PFS and OS were better than with temsirolimus but lower than with sunitinib or with the combination of bevacizumab and interferon.

As pegylated IFNs are more convenient to use than non-pegylated IFN, they might find their place and more regular use in the treatment of RCC patients in combination with bevacizumab or in the second line treatment after TKIs in the current combination. Usually, TKIs are more tolerable than this study combination but with lower starting dose of capecitabine the situation can be different. With lower dose of capecitabine most of the clinically significant grade 4 side effects are probably prevented. As the clinical benefit was clear, we recommend a phase-III study to clarify the position of the current study combination.

\section{Conclusions}

The combination of capecitabine and pegylated interferon-alfa-2a produced clinical benefit of $69 \%$, including $23 \%$ PRs and $4 \%$ CRs. Three responders had only pulmonary metastases and three had lymph node metastases, one patient had multiple sites. However, the response rate was not better than in studies including non-pegylated interferon. The median PFS was 7.5 months and OS 17 months. Dose reductions were needed in $85 \%$ of patients and dose delays in $46 \%$, which is in line with previous studies. Toxicity was still manageable, but because of many reductions the dose for capecitabine should be $1600 \mathrm{mg} / \mathrm{m}^{2}$ per day in the future studies. The most common toxicities were fatigue, nausea, hematological toxicities and elevated liver values. Because of more convenient dosing, the pegylated interferon-alfa-2a would be useful to be studied in combination with bevacizumab. The current combination might be applicable in the second line treatment after TKIs, but a phase-III study is still needed. At the moment, patients unsuitable to treatment with sunitinib or bevacizumab (such as hypertensive patients or cases with previous arterial thromboembolic event or gastrointestinal perforation) could be candidates for this combination.

\section{References}

1. Quesada JR, Swanson DA, Trindade A, Gutterman JU (1983) Renal cell carcinoma: Antitumor effects of leukocyte interferon. Cancer Res 43(2):940-947. 
2. Tagliaferri P, Caraglia M, Budillon A, et al. (2005) New pharmacokinetic and pharmacodynamic tools for interferon-alpha (IFN-alpha) treatment of human cancer. Cancer Immunol Immunother 54:1-10.

3. Motzer RJ, Rakhit A, Ginsberg M, et al. (2001) Phase I trial of 40-kd branched pegylated interferon alfa-2a for patients with advanced renal cell carcinoma. J Clin Oncol 19(5):1312-1319.

4. Talpaz M, O'Brien S, Rose $E$, et al. (2001) Phase 1 study of polyethylene glycol formulation of interferon-alfa-2B (Schering 54031) in Philadelphia chromosome-positive chronic myelogenous leukemia. Blood 98(6):1708-1713.

5. Motzer RJ, Rakhit A, Thompson J, et al. (2002) Phase II trial of branched peginterferon-alfa 2 a (40 kd) for patients with advanced renal cell carcinoma. Ann Oncol 13:1799-1805.

6. Bukowski R, Ernstoff MS, Gore ME, et al. (2002) Pegylated interferon Alfa-2b treatment for patients with solid tumors: A phase I/II study. J Clin Oncol 20(18):3841-3849.

7. Bex A, Mallo H, Kerst M, Haanen J, Horenblas S, de Gast GC. A phase-II study of pegylated interferon alfa-2b for patients with metastatic renal cell carcinoma and removal of the primary tumor. Cancer Immunol Immunother 54:713-719.

8. Motzer RJ, Russo P (2000) Systemic therapy for renal cell carcinoma. J Urol 163:408-417.

9. Kish JA, Wolf M, Crawford ED, et al. (1994) Evaluation of low dose continuous infusion 5-fluorouracil in patients with advanced and recurrent renal cell carcinoma. A Southwest Oncology Group Study. Cancer 74(3):916-919.

10. Miwa M, Ura M, Nishida M, et al. (1998) Design of a novel oral fluoropyrimidine carbamate, capecitabine, which generates 5 -fluorouracil selectively in tumours by enzymes concentrated in human liver and cancer tissue. Eur J Cancer 34(8):1274-1281.

11. Pagliaro LC, Perez CA, Tu SM, Daliani DD (2006) Phase II study of capecitabine singe-agent therapy in patients with metastatic renal cell carcinoma. Urol Oncol 24:487-491.

12. Petrioli R, Paolelli L, Francini E, et al. (2007) Capecitabine as third-line treatment in patients with metastatic renal cell carcinoma after failing immunotherapy. Anticancer Drugs 18(7):817-820.

13. Eda H, Fujimoto K, Watanabe S, et al. (1993) Cytokines induce thymidine phosphorylase expression in tumor cells and make them more susceptible to 5'-deoxy-5-fluorouridine. Cancer Chemother Pharmacol 32:333-338.

14. Morita T, Tokue A (1999) Biomodulation of 5-fluorouracil by interferon-alfa in human renal carcinoma cells: relationship to the expression of thymidine phosphorylase. Cancer Chemother Pharmacol 44:91-96.

15. Gebrosky NP, Koukol S, Nseyo UO, Carpenter C, Lamm DL (1997) Treatment of renal cell carcinoma with 5-fluorouracil and alfa-interferon. Urology 50(6):863-868.

16. Negrier S, Caty A, Lesimple T, et al. (2000) Treatment of patients with metastatic renal carcinoma with a combination of subcutaneous interleukin-2 and interferon alfa with or without fluorouracil. J Clin Oncol 18(24):4009-4015.

17. Chang DZ, Olencki T, Budd GT, et al. (2001) Phase I trial of capecitabine in combination with interferon alpha in patients with metastatic renal cancer: toxicity and pharmacokinetics. Cancer Chemother Pharmacol 48:493-498.

18. Padrik P, Leppik K, Arak A (2004) Combination therapy with capecitabine and interferon alfa-2A in patients with advanced renal cell carcinoma: a phase II study. Urol Oncol 22:387-392. 
19. Segota E, Mekhail T, Olencki T, et al. (2007) Phase II trial of capecitabine and rHU-interferon-alfa-2a in patients with metastatic renal cell carcinoma, limited efficacy, and moderate toxicity. Urol Oncol 25:4652.

20. Wenzel C, Locker GJ, Bartsch R, et al. (2003) Capecitabine monotherapy and in combination with immunotherapy in the treatment of metastatic renal cell carcinoma. Anticancer Drugs 14(10):779-784.

21. Wenzel C, Locker GJ, Schmidinger M, et al. (2002) Capecitabine in the treatment of metastatic renal cell carcinoma failing immunotherapy. Am J Kidney Dis 39(1):48-54.

22. Amato RJ, Rawat A (2006) Interferon-alfa plus capecitabine and thalidomide in patients with metastatic renal cell carcinoma: A pilot study. Invest New Drugs 24:171-175.

23. Oovermann K, Buer J, Hoffman R, et al. (2000) Capecitabine in the treatment of metastatic renal cell carcinoma. Br J Cancer 2000;83(5):583-587.

24. Recchia F, Saggio G, Amiconi G, et al. (2007) Multicenter phase II study of chemo-immunotherapy in the treatment of metastatic renal cell carcinoma. J Immunother 30(4):448-454.

25. Therasse P, Arbuck SG, Eisenhauer EA, et al. (2000) New guidelines to evaluate the response to treatment in solid tumors. J Natl Cancer Inst 92(3):205-216.

26. NCI-CTCAE, available in

htpp://ctep.cancer.gov/protocolDevelopment/electronic_applications/docs/ctcaev3.pdf

27. Aaronson NK, Ahmedzai S, Bergman B, et al. (1993) The European Organisation for Research and Treatment of Cancer QLQ-C30: A quality-of-life instrument for use in international clinical trials in oncology. J Natl Cancer Inst 85:365-376.

28. Rini BI, Weinberg V, Small EJ (2005) A phase I trial of fixed dose rate gemcitabine and capecitabine in metastatic renal cell carcinoma. Cancer 103(3):553-558.

29. Waters JS, Moss C, Pyle L, et al. (2004) Phase II clinical trial of capecitabine and gemcitabine chemotherapy in patients with metastatic renal carcinoma. Br J Cancer 91:1763-1768.

30. Clark JI, Mehrabi J, Sosman JA, et al. (2007) Phase I/II trial of outpatient PEG-interferon with interleukin-2 in advanced renal cell carcinoma: a Cytokine Working Group Study. J Immunother 30(8):839-846.

31. George S, Hutson TE, Mekhail T, et al. (2008) Phase I trial of PEG-interferon and recombinant IL-2 in patients with metastatic renal cell carcinoma. Cancer Chemother Pharmacol 62:347-354.

\title{
32. NCCN Clinical Practice Guidelines in Oncology. Kidney Cancer V.I.2010. Available in htpp://www.nccn.org.
}

33. Escudier B, Pluzanska A, Koralewski P, et al. (2007) Bevacizumab plus interferon alfa-2a for treatment of metastatic renal cell carcinoma: a randomised, double-blind phase III trial. Lancet 370: 2103-2111.

\author{
34. Motzer RJ, Hutson TE, Tomczak P, et al. (2007) Sunitinib versus interferon alfa in \\ metastatic renal-cell carcinoma. NEJM 356(2): 115-124.
}

35. Motzer RJ, Hutson TE, Tomczak P, et al. (2009) Overall survival and updated results for sunitinib compared with interferon alfa in patients with metastatic renal cell carcinoma. $J$ Clin Oncol 27(22): 3584-3590.

36. Hudes G, Carducci M, Tomczak P, et al. (2007) Temsirolimus, interferon alfa, or both for advanced renal-cell carcinoma. NEJM 356(22): 2271-2281. 
Table 1. Patient demographics

\begin{tabular}{|l|l|c|c|}
\hline Demographics & & $\mathrm{N}$ & $(\%)$ \\
\hline Sex & Female & 10 & $(38)$ \\
& Male & 16 & $(62)$ \\
\hline Zubrod & 0 & 10 & $(38)$ \\
& 1 & 16 & $(62)$ \\
\hline Palliative radiotherapy & Given & 5 & $(19)$ \\
& Not given & 21 & $(81)$ \\
\hline Primary nephrectomy & Radical & 12 & $(46)$ \\
& Non-radical & 12 & $(46)$ \\
& Not done & 2 & $(\mathbf{8})$ \\
\hline Grade of the primary tumor & G1 & 0 & $(0)$ \\
& G2 & 8 & $(31)$ \\
& G3 & 4 & $(15)$ \\
& G4 & 12 & $(46)$ \\
& Not specified & 2 & $(8)$ \\
\hline T class of the primary tumor & T1 & 1 & $(4)$ \\
& T2 & 6 & $(23)$ \\
& T3 & 16 & $(62)$ \\
& T4 & 1 & $(4)$ \\
& Not specified & 2 & $(8)$ \\
\hline N class of the primary tumor & 0 & 10 & $(38)$ \\
& 1 & 3 & $(12)$ \\
& 2 & 2 & $(8)$ \\
& Not available & 11 & $(42)$ \\
\hline M status of the patients & Primarily metastatic & 13 & $(50)$ \\
& Single site of metastases & 9 & $(35)$ \\
& Multiple sites of metastases & 17 & $(65)$ \\
& Abdominal metastases & 13 & $(50)$ \\
& Pulmonary or mediastinal & 19 & $(73)$ \\
& Lymph nodes, soft tissues & 12 & $(46)$ \\
& Other & 4 & $(15)$ \\
\hline
\end{tabular}


Table 2. Clinical toxicity

\begin{tabular}{|c|c|c|c|c|c|}
\hline Toxicity & Grade & \multicolumn{2}{|c|}{ Per patient n (\%) } & \multicolumn{2}{|c|}{ Per cycle n (\%) } \\
\hline Fatigue & $\begin{array}{l}0 \\
1-2 \\
3-4\end{array}$ & $\begin{array}{c}1 \\
19 \\
6\end{array}$ & $\begin{array}{c}(4) \\
(73) \\
(23)\end{array}$ & $\begin{array}{c}62 \\
115 \\
6\end{array}$ & $\begin{array}{c}(34) \\
(63) \\
(3)\end{array}$ \\
\hline Muscle pain & $\begin{array}{l}0 \\
1-2 \\
3-4\end{array}$ & $\begin{array}{c}19 \\
7 \\
0\end{array}$ & $\begin{array}{c}(73) \\
(27) \\
(0)\end{array}$ & $\begin{array}{c}148 \\
35 \\
0\end{array}$ & $\begin{array}{c}(81) \\
(19) \\
(0)\end{array}$ \\
\hline Fever & $\begin{array}{l}0 \\
1-2 \\
3-4\end{array}$ & $\begin{array}{c}13 \\
13 \\
0\end{array}$ & $\begin{array}{c}(50) \\
(50) \\
(0)\end{array}$ & $\begin{array}{c}153 \\
30 \\
0\end{array}$ & $\begin{array}{c}(84) \\
(16) \\
(0)\end{array}$ \\
\hline Neuropathy & $\begin{array}{l}0 \\
1-2 \\
3-4\end{array}$ & $\begin{array}{c}17 \\
9 \\
0\end{array}$ & $\begin{array}{c}(65) \\
(35) \\
(0)\end{array}$ & $\begin{array}{c}157 \\
26 \\
0\end{array}$ & $\begin{array}{c}(86) \\
(14) \\
(0)\end{array}$ \\
\hline Constipation & $\begin{array}{l}0 \\
1-2 \\
3-4\end{array}$ & $\begin{array}{c}12 \\
13 \\
1 \\
\end{array}$ & $\begin{array}{c}(46) \\
(50) \\
(4)\end{array}$ & $\begin{array}{c}156 \\
26 \\
1 \\
\end{array}$ & $\begin{array}{c}(85) \\
(14) \\
(1)\end{array}$ \\
\hline Stomatitis & $\begin{array}{l}0 \\
1-2 \\
3-4\end{array}$ & $\begin{array}{c}15 \\
10 \\
1\end{array}$ & $\begin{array}{c}(58) \\
(38) \\
(4)\end{array}$ & $\begin{array}{c}161 \\
21 \\
1\end{array}$ & $\begin{array}{c}(88) \\
(11) \\
(1)\end{array}$ \\
\hline $\begin{array}{l}\text { Nausea and } \\
\text { vomiting }\end{array}$ & $\begin{array}{l}0 \\
1-2 \\
3-4\end{array}$ & $\begin{array}{c}3 \\
20 \\
3 \\
\end{array}$ & $\begin{array}{l}(12) \\
(77) \\
(12)\end{array}$ & $\begin{array}{c}124 \\
56 \\
3 \\
\end{array}$ & $\begin{array}{c}(68) \\
(31) \\
(2)\end{array}$ \\
\hline Diarrhea & $\begin{array}{l}0 \\
1-2 \\
3-4\end{array}$ & $\begin{array}{c}12 \\
10 \\
4\end{array}$ & $\begin{array}{l}(46) \\
(38) \\
(15)\end{array}$ & $\begin{array}{c}157 \\
22 \\
4\end{array}$ & $\begin{array}{c}(86) \\
(12) \\
(2)\end{array}$ \\
\hline Infection & $\begin{array}{l}0 \\
1-2 \\
3-4\end{array}$ & $\begin{array}{c}13 \\
13 \\
0\end{array}$ & $\begin{array}{c}(50) \\
(50) \\
(0)\end{array}$ & $\begin{array}{c}160 \\
23 \\
0\end{array}$ & $\begin{array}{c}(87) \\
(13) \\
(0)\end{array}$ \\
\hline Alopecia & $\begin{array}{l}0 \\
1-2 \\
3-4\end{array}$ & $\begin{array}{c}21 \\
5 \\
0\end{array}$ & $\begin{array}{c}(81) \\
(19) \\
(0)\end{array}$ & $\begin{array}{c}171 \\
12 \\
0\end{array}$ & $\begin{array}{c}(93) \\
(7) \\
(0)\end{array}$ \\
\hline Rash & $\begin{array}{l}0 \\
1-2 \\
3-4 \\
\end{array}$ & $\begin{array}{c}13 \\
13 \\
0 \\
\end{array}$ & $\begin{array}{c}(50) \\
(50) \\
(0)\end{array}$ & $\begin{array}{c}146 \\
37 \\
0 \\
\end{array}$ & $\begin{array}{c}(80) \\
(20) \\
(0)\end{array}$ \\
\hline Allergic symptoms & $\begin{array}{l}0 \\
1-2 \\
3-4\end{array}$ & $\begin{array}{c}26 \\
0 \\
0\end{array}$ & $\begin{array}{c}(100) \\
(0) \\
(0)\end{array}$ & $\begin{array}{c}183 \\
0 \\
0\end{array}$ & $\begin{array}{c}(100) \\
(0) \\
(0)\end{array}$ \\
\hline Hand-foot syndrome & $\begin{array}{l}0 \\
1-2 \\
3-4\end{array}$ & $\begin{array}{c}15 \\
10 \\
1\end{array}$ & $\begin{array}{c}\mathbf{( 5 8 )} \\
(38) \\
(4)\end{array}$ & $\begin{array}{c}112 \\
70 \\
1\end{array}$ & $\begin{array}{c}(61) \\
(38) \\
(1)\end{array}$ \\
\hline Other symptoms & $\begin{array}{l}0 \\
1-2 \\
3-4\end{array}$ & $\begin{array}{c}6 \\
18 \\
2\end{array}$ & $\begin{array}{c}(23) \\
(69) \\
(8)\end{array}$ & $\begin{array}{c}130 \\
51 \\
2\end{array}$ & $\begin{array}{c}(71) \\
(28) \\
(1)\end{array}$ \\
\hline
\end{tabular}


Table 3. Hematological and serum chemistry toxicity.

\begin{tabular}{|c|c|c|c|c|c|}
\hline \multirow{2}{*}{$\begin{array}{l}\text { Value } \\
\text { Anemia }\end{array}$} & \multirow{2}{*}{$\begin{array}{l}\text { Grade } \\
0\end{array}$} & \multicolumn{2}{|c|}{ Per patient n (\%) } & \multicolumn{2}{|c|}{ Per cycle n (\%) } \\
\hline & & 9 & $(35)$ & 84 & (46) \\
\hline & $1-2$ & 17 & $(65)$ & 99 & (54) \\
\hline & $3-4$ & 0 & $(0)$ & 0 & $(0)$ \\
\hline \multirow[t]{3}{*}{ Leukopenia } & 0 & 8 & (31) & 116 & (63) \\
\hline & $1-2$ & 17 & (65) & 66 & (36) \\
\hline & $3-4$ & 1 & (4) & 1 & (1) \\
\hline \multirow[t]{3}{*}{ Neutropenia } & 0 & 10 & (38) & 100 & (55) \\
\hline & $1-2$ & 15 & $(58)$ & 82 & (45) \\
\hline & $3-4$ & 1 & $(1)$ & 1 & (1) \\
\hline \multirow[t]{3}{*}{ Thrombocytopenia } & 0 & 13 & (50) & 99 & (54) \\
\hline & $1-2$ & 13 & $(50)$ & 84 & (46) \\
\hline & $3-4$ & 0 & $(0)$ & 0 & $(0)$ \\
\hline \multirow[t]{3}{*}{ S-AFOS } & 0 & 19 & (73) & 158 & (86) \\
\hline & $1-2$ & 7 & (27) & 25 & (14) \\
\hline & $3-4$ & 0 & $(0)$ & 0 & $(0)$ \\
\hline \multirow[t]{4}{*}{ S-ASAT } & 0 & 10 & (38) & 117 & (64) \\
\hline & $1-2$ & 15 & (58) & 64 & (35) \\
\hline & $3-4$ & 1 & $(4)$ & 1 & (1) \\
\hline & ND & & & 1 & (1) \\
\hline \multirow[t]{3}{*}{ S-ALAT } & 0 & 15 & (58) & 146 & (80) \\
\hline & $1-2$ & 11 & (42) & 37 & (20) \\
\hline & $3-4$ & 0 & $(0)$ & 0 & $(0)$ \\
\hline \multirow[t]{4}{*}{ S-GT } & 0 & 13 & $(52)$ & 109 & (60) \\
\hline & $1-2$ & 11 & (44) & 62 & (34) \\
\hline & $3-4$ & 1 & $(4)$ & 1 & (1) \\
\hline & ND & & & 11 & (6) \\
\hline \multirow[t]{4}{*}{ S-Krea } & 0 & 13 & (50) & 152 & (83) \\
\hline & $1-2$ & 13 & (50) & 30 & (16) \\
\hline & $3-4$ & 0 & $(0)$ & 0 & $(0)$ \\
\hline & ND & & & 1 & (1) \\
\hline \multirow[t]{4}{*}{ Hypocalcemia } & 0 & 6 & (23) & 105 & (57) \\
\hline & $1-2$ & 20 & (77) & 78 & (43) \\
\hline & $3-4$ & 0 & $(0)$ & 0 & $(0)$ \\
\hline & ND & & & 1 & (1) \\
\hline \multirow[t]{3}{*}{ Hypercalcemia } & 0 & 24 & (92) & 180 & (98) \\
\hline & $1-2$ & 2 & $(8)$ & 3 & (2) \\
\hline & $3-4$ & 0 & $(0)$ & 0 & $(0)$ \\
\hline \multirow[t]{4}{*}{ S-Alb } & 0 & 5 & (19) & 98 & (54) \\
\hline & $1-2$ & 21 & (81) & 82 & (45) \\
\hline & $3-4$ & 0 & $(0)$ & 0 & (0) \\
\hline & ND & & & 3 & (2) \\
\hline
\end{tabular}

ND not done 
Table 4. The dose reductions

\begin{tabular}{|c|c|c|c|c|c|}
\hline \multirow{7}{*}{$\begin{array}{l}\text { Dose reductions to } \\
\text { capecitabine }\end{array}$} & \multirow{7}{*}{$\begin{array}{l}\text { None } \\
\text { Once } \\
\text { Twice } \\
\text { Three times } \\
\text { Four times } \\
\text { Five times }\end{array}$} & \multicolumn{2}{|c|}{ Per patient $(\%)$} & \multicolumn{2}{|c|}{ Per cycle $(\%)$} \\
\hline & & 4 & $(15)$ & 71 & (39) \\
\hline & & 13 & (50) & 72 & (39) \\
\hline & & 4 & (15) & 21 & (11) \\
\hline & & 3 & (12) & 14 & (8) \\
\hline & & 1 & (4) & 2 & (1) \\
\hline & & 1 & (4) & 3 & \\
\hline \multirow{14}{*}{$\begin{array}{l}\text { Reasons for dose } \\
\text { reductions of } \\
\text { capecitabine }\end{array}$} & \multirow{14}{*}{$\begin{array}{l}\text { Anemia } \\
\text { Leucopenia } \\
\text { Elevation of liver values } \\
\text { Lowered general condition } \\
\text { Diarrhea } \\
\text { Neutropenia } \\
\text { Nausea } \\
\text { Hand-foot-syndrome } \\
\text { Thrombocytopenia } \\
\text { Rash } \\
\text { Vacation } \\
\text { Stomatitis } \\
\text { Multiple reasons }\end{array}$} & \multicolumn{4}{|c|}{ Number of reductions } \\
\hline & & \multicolumn{4}{|c|}{2} \\
\hline & & \multicolumn{4}{|c|}{2} \\
\hline & & \multicolumn{4}{|c|}{10} \\
\hline & & \multicolumn{4}{|c|}{5} \\
\hline & & \multicolumn{4}{|c|}{2} \\
\hline & & \multicolumn{4}{|c|}{18} \\
\hline & & \multicolumn{4}{|c|}{1} \\
\hline & & \multicolumn{4}{|c|}{4} \\
\hline & & \multicolumn{4}{|c|}{3} \\
\hline & & \multicolumn{4}{|c|}{2} \\
\hline & & \multicolumn{4}{|c|}{1} \\
\hline & & \multicolumn{4}{|c|}{1} \\
\hline & & \multicolumn{4}{|c|}{9} \\
\hline \multirow{7}{*}{$\begin{array}{l}\text { Dose intensity of } \\
\text { capecitabine }\end{array}$} & \multirow{7}{*}{$\begin{array}{l}90-100 \% \\
80-89 \% \\
70-79 \% \\
60-69 \% \\
50-59 \% \\
40-49 \%\end{array}$} & \multicolumn{4}{|c|}{ Cycles (\%) } \\
\hline & & \multirow{6}{*}{\multicolumn{2}{|c|}{$\begin{array}{c}73 \\
9 \\
65 \\
6 \\
26 \\
4\end{array}$}} & \multicolumn{2}{|c|}{ (40) } \\
\hline & & & & & \\
\hline & & & & & \\
\hline & & & & & \\
\hline & & & & & \\
\hline & & & & & \\
\hline \multirow{3}{*}{$\begin{array}{l}\text { Reduction to pegylated } \\
\text { interferon-alfa- } 2 \mathrm{a}\end{array}$} & \multirow{3}{*}{$\begin{array}{l}\text { Done } \\
\text { Not done }\end{array}$} & \multicolumn{2}{|c|}{ Per patient $(\%)$} & \multicolumn{2}{|c|}{ Per cycle $(\%)$} \\
\hline & & 9 & $(35)$ & 160 & $(87)$ \\
\hline & & 17 & $(65)$ & 23 & (13) \\
\hline
\end{tabular}


Fig. 1. Kaplan-Meier estimates of overall and progression-free survival.

Fig. 2. Results of quality-of-life -questionnaire in base line (L1), in cycle 5 (L5) and in cycle 10 (L10).

0.9

0.8

0.7

0.6

0.5

0.4

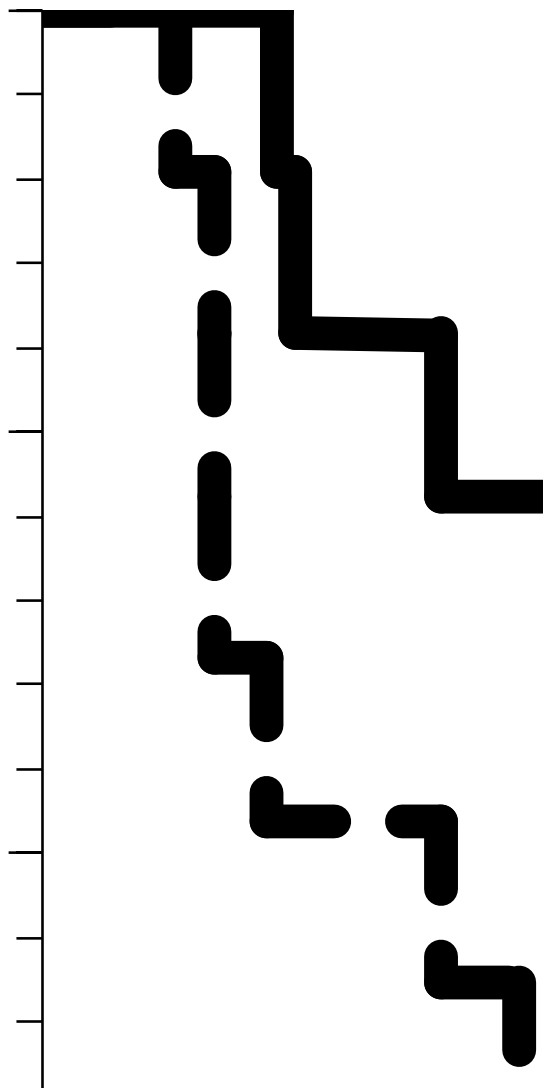

0.3

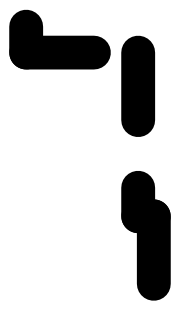


120

100

80

60

in

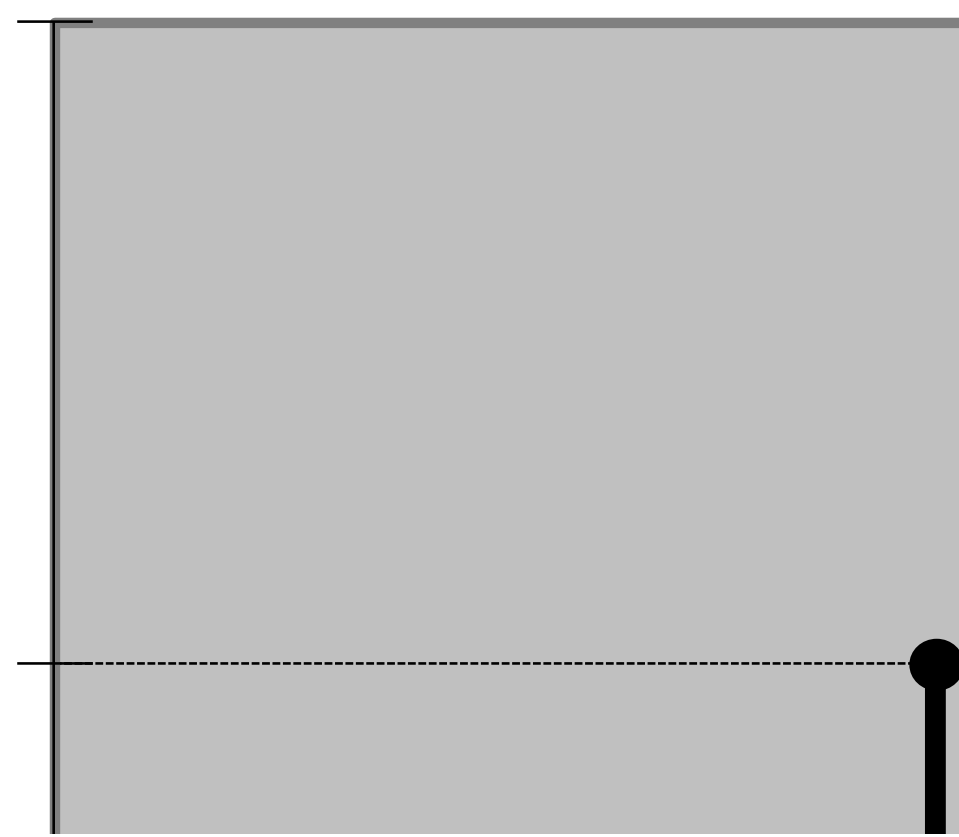

